\title{
A Study of Variant Anatomy of Gonadal Arteries in 40 Adult Males: A Cross-sectional Cadaveric Study
}

\section{ABSTRACT}

Introduction: The surgeons are witnessing an ever-increasing range of operative procedures with increasing levels of complexity in the abdominal cavity. So, the anatomy of blood vessels of abdominal cavity has assumed much more importance. Knowledge of variations in the gonadal artery is essential during renal and gonadal surgery as these variations may influence the blood flow to the kidney and gonads and cause some pathological conditions such as varicocoele and gonadal atrophy.

Aim: To assess the prevalence of variations in origin and course of the gonadal arteries and to discuss their clinical significance.

Materials and Methods: This cross-sectional cadaveric study was done in 40 human cadavers which were well embalmed and allotted for under graduate teaching in the Department of Anatomy, Madurai Medical College Madurai, Tamil Nadu, India, from the year June 2010 to May 2015. The human cadavers were numbered serially from 1-40. The routine dissection of abdomen was done. The origin and course of the gonadal arteries were traced. Variations in number, origin and course of the gonadal arteries were noted. The incidence of gonadal artery arising from the renal artery was calculated. Prevalence of variant origin of gonadal artery from renal artery was noted. Software of MacBook pages was used to gather the data. Categorical data were presented as mean and percentage.

Results: In the present study, in 36 cadavers (90\%) the gonadal artery was normal in source of origin, and took normal course in 39 cadavers $(97.5 \%)$. In the remaining cadavers different variations were observed. The variations found in this study include the gonadal arteries arising from the renal artery $4(10 \%)$ cadavers and according with course arching of left gonadal artery over the left renal vein seen in $1(2.5 \%)$ cadaver. In the current study, the vertebral level of origin of the artery ranged from the intervertebral disc of first and second lumbar vertebra to upper $1 / 3^{\text {rd }}$ of the third lumbar vertebra on the right-side and between upper $1 / 3^{\text {rd }}$ of first lumbar to lower $1 / 3^{\text {rd }}$ of third vertebra on the left-side.

Conclusion: During surgical and diagnostic interventions at the level of renal, gonadal and para aortic vessels arterial variations are clinically important to avoid risk of haemorrhage, ischaemia of particular organs. Those arterial variations are not only unilateral but also bilateral associations of vascular anomaly must be considered.

Keywords: Arched testicular artery, Renal artery origin, Vascular variations

\section{INTRODUCTION}

Now-a-days many advanced new operative techniques like endovascular and curative surgeries have been done within the abdominal cavity. One of the prerequisites for successful and safe surgery is not only a good understanding of the underlying anatomy but also having awareness of the variations in anatomy that may present itself during operative procedures. This is particularly important during renal and gonadal surgery as these anatomical variations can affect blood supply to these crucial organs and can determine success and complications after surgery [1]. The paired gonadal arteries originate at L2 level from the abdominal aorta. They are long slender vessels which slant down over the abdominal aorta and then lateral to it. They pass over the psoas muscles on a line directed to the deep inguinal ring. Anomalies of gonadal arteries include variations in their origin, number and course. The gonadal artery originated from the main or accessory renal artery in 5-6\% of the cases and is referred as an aberrant gonadal artery [1]. Among all the paired and unpaired branches of abdominal aorta renal artery variations are common [2-4]. Many case reports on variations in the gonadal arteries were reported incidentally during the studies of branching pattern of abdominal aorta and studies of variations in renal arteries [2-5]. Course of the gonadal arteries in relation to the renal pedicle was classified by Notkovitch [6] three types-
Type I (84\%): The gonadal artery arises from aorta behind or below the renal vein; may pass anterior or posterior to inferior vena cava.

Type II (6\%): The gonadal artery arises from the aorta above the level of renal vein; always pass posterior to inferior venacava on the right-side.

Type III (8\%): Gonadal artery after its origin from the aorta below the level of renal vein, it makes a loop over the renal vein and then it pass forwards. It is called as Arched Gondal artery which is of surgical importance. According to the origin and number of gonadal arteries another classification was done by Ciçekcibaşi AE et al., [7]. Certain anomalies of kidneys are associated with variation of gonadal arteries as both of them share common embryological origin [8]. Hence, this study was conducted to observe the variations in the origin of gonadal arteries in 40 male cadavers.

\section{MATERIALS AND METHODS}

The cross-sectional cadaveric study was conducted in Institute of Anatomy, Madurai Medical College, Tamil Nadu, India, from June 2010 to May 2015. The study was done in 40 human cadavers which were well embalmed and allotted for under graduate teaching in the Institute of Anatomy, Madurai Medical College Madurai. Since the study was conducted in human cadavers allotted for undergraduate teaching of first year MBBS students there was no ethical issues. 
Inclusion criteria: The cadaver which were well embalmed male, not damaged was selected for the study.

Exclusion criteria: The cadavers which were female sex, damaged and not well embalmed and very old cadavers were excluded for the study.

The human cadavers were numbered serially from 1 to 40 . Manual dissection was done in all 40 cadavers according to Romanes GJ and Cunningham S, Cunninghan's manual [9].

\section{Dissection Procedure}

The routine dissection of abdomen was done for educational purposes abdominal cavity was opened by cutting and reflecting the anterior abdominal wall muscles. Abdominal visceras were mobilised to expose the origin of important branches of abdominal aorta. The origin and course of the gonadal arteries were traced. Variations in number, origin and course of the gonadal arteries were noted.

All the cadavers were donors and both direct and informed consent were obtained by the institute for their bodies to use for teaching and research purposes.

\section{STATISTICAL ANALYSIS}

Software of MacBook pages was used to gather the data. Categorical data were presented as number and percentage.

\section{RESULTS}

Forty male cadavers which were selected for the study, aged between 35 to 60 years the following observations were seen. In $35(87.5 \%)$ cases gonadal artery was normal in its origin, number and course. In the remaining $5(12.5 \%)$ cases different variations were observed which were stated as below.

\section{Source of Origin}

- In 36 out of 40 cadavers the gonadal artery was seen arising from abdominal aorta.

- In the remaining four cadavers, gonadal artery of renal origin was present [Table/Fig-1-4]. Among them in two cadavers double gonadal arteries were seen.

In one cadaver the variant origin of gonadal artery was bilateralsingle on the right-side double on the left-side [Table/Fig-1]. In this cadaver bilateral accessory renal arteries and bilateral renal origin of gonadal arteries were seen [Table/Fig-1]. On the left-side double gonadal arteries were presented as superior testicular artery originating from the main renal artery and inferior testicular artery arising from abdominal aorta just below. The accessory renal artery [Table/Fig-1]. On the right-side single gonadal artery originated from the upper renal artery.

In three cadavers the variant origin of gonadal artery was unilateral. In one cadaver single gonadal artery was arising from the right renal artery [Table/Fig-2]. In another cadaver single gonadal artery was originated from the upper hilar branch of left renal artery [Table/ Fig-3]. In one cadaver on the right-side, the double gonadal arteries one as a medial artery and another as a lateral artery originated from the renal artery [Table/Fig-4]. Gonadal artery arising from coeliac trunk, superior mesenteric artery or middle suprarenal artery was not seen. The incidence of gonadal artery arising from renal artery was thus $10.0 \%$. The incidence of variant origin of gonadal artery from renal artery was shown in [Table/Fig-5].

\section{Vertebral Level of Origin}

In the current study, of 40 male cadavers, the vertebral level of origin of the artery ranged from the intervertebral disc of first and second lumbar vertebra to upper $1 / 3^{\text {rd }}$ of the third lumbar vertebra on the right-side and between upper $1 / 3^{\text {rd }}$ of first lumbar to lower $1 / 3^{\text {rd }}$ of third vertebra on the left-side.

In 33 out of 40 cadavers both right and left gonadal arteries were originated at the level of second lumbar vertebra.

- In two cadavers right gonadal artery was originated at the level of intervertebral disc of first and second lumbar vertebra and the level of left gonadal artery was upper $1 / 3^{\text {rd }}$ of first lumbar vertebra.

- In one cadaver the vertebral level of right gonadal artery was upper $1 / 3^{\text {rd }}$ of third lumbar vertebra and the level of left gonadal artery was lower $1 / 3^{\text {rd }}$ of third lumbar vertebra.

- In four cadavers variant origin of gonadal arteries from renal arteries had their vertebral level corresponding to level of renal arteries.

\section{Course of Gonadal Arteries}

In this study, out of 40 cases, 39 shows normal course. In all these 39 cases each artery runs obliquely downwards and posterior to the peritoneum on the psoas major muscle. Descending on the
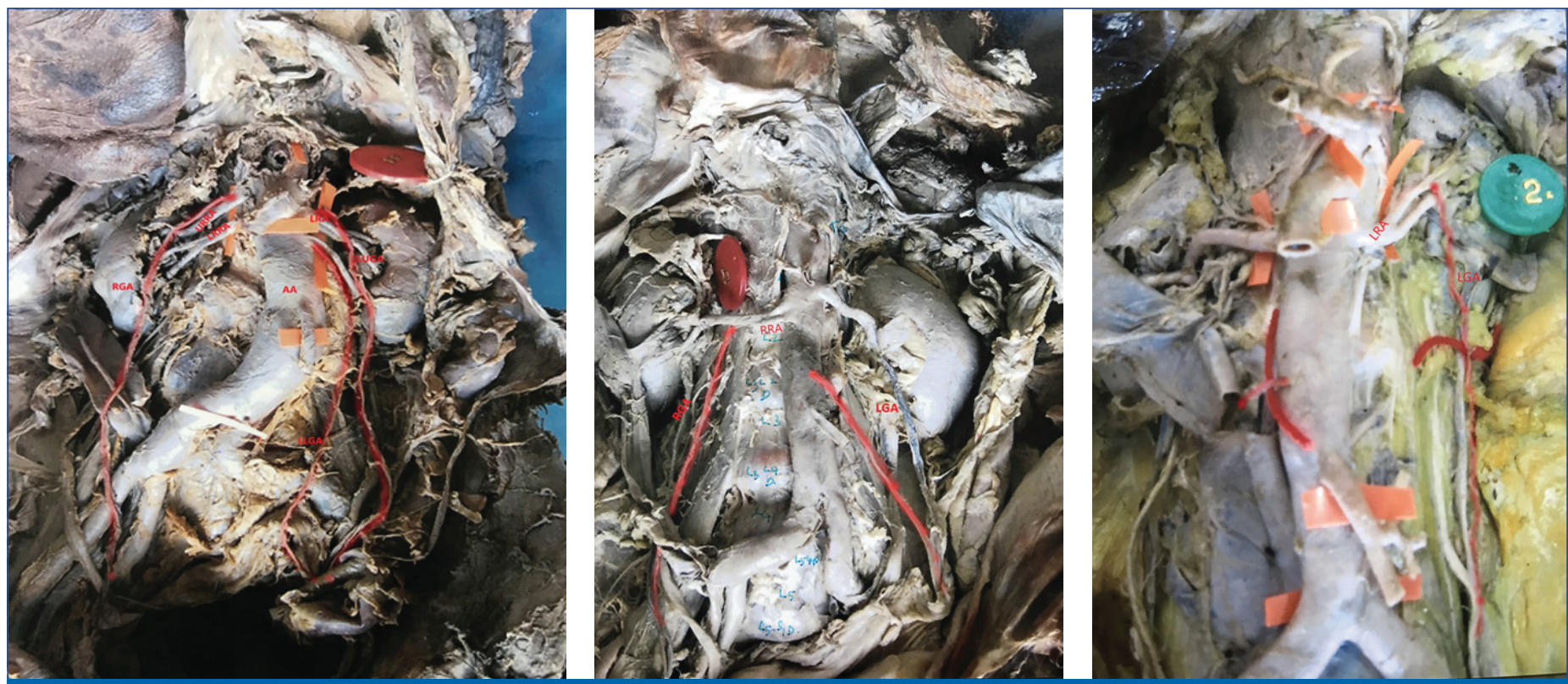

[Table/Fig-1]: Double gonadal arteries on the left side. Left upper gonadal artery arising from the left renal artery and left lower gonadal artery arising from the aorta. right gonadal artery arising from the upper right renal artery; [Table/Fig-2]: Shows right gonadal artery arising from the right renal artery and left gonadal artery from the aorta; [Table/Fig-3]: Shows left gonadal artery arising from the left renal artery. (Images from left to right) 


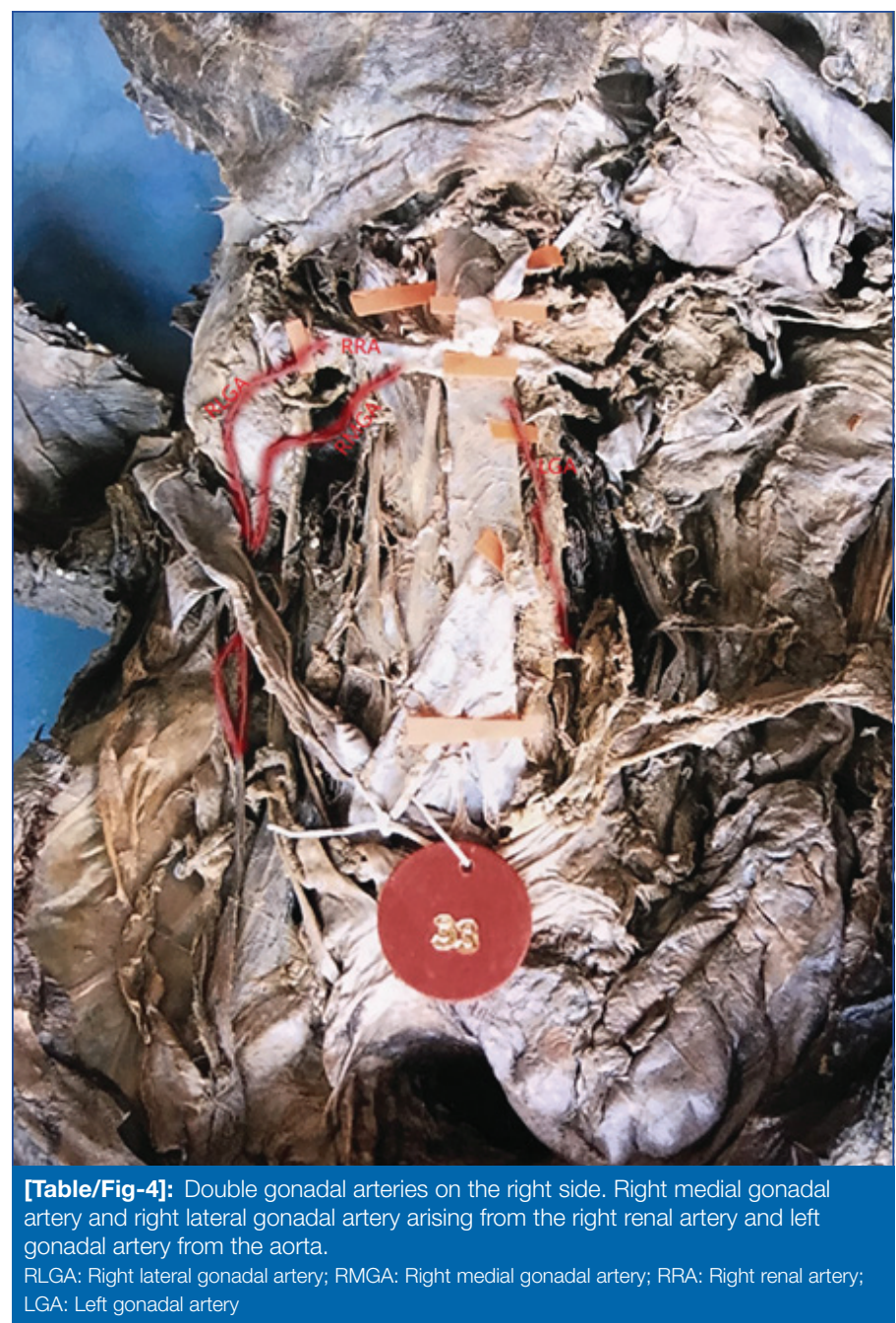

Normal (aorta): 36 Variation (renal artery):4

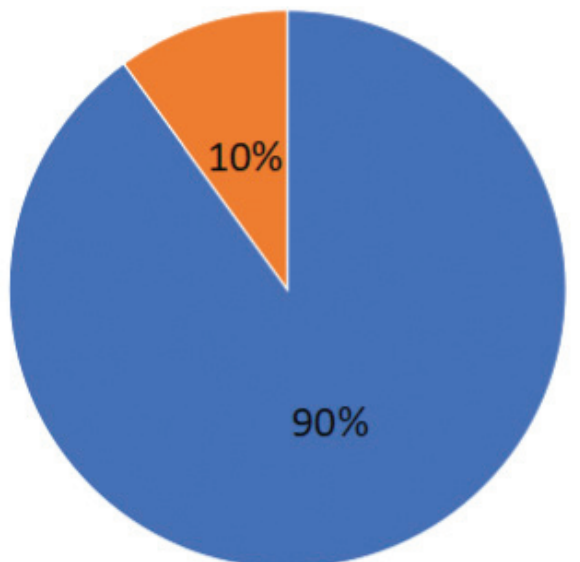

[Table/Fig-5]: Incidence of gonadal artery origin from renal artery.

posterior abdominal wall, each testicular artery enters the inguinal canal through the deep inguinal ring. According to left gonadal artery in one case the left gonadal artery took its origin from the abdominal aorta distal to the origin of renal artery and then instead of descending it ascended upwards behind the left renal vein and then loops at its upper border to run downwards accompanying the testicular vein [Table/Fig-6]. According to Notkovitch $\mathrm{H}$ this type is called as arched testicular artery of Luschka [6].

\section{DISCUSSION}

In the present study, among the 40 male cadavers, the gonadal artery was originated from the abdominal aorta in 36 cadavers

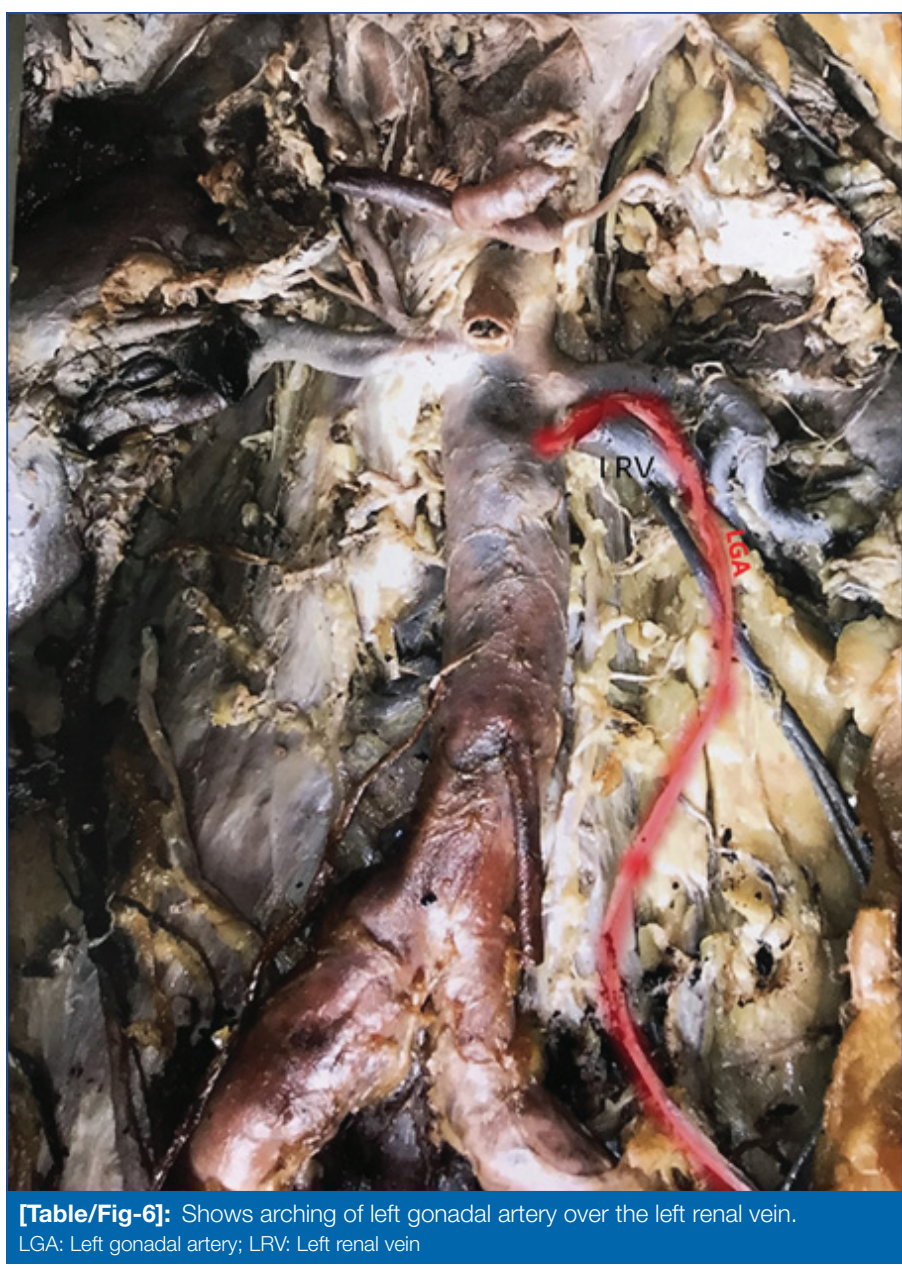

(90\%), single on each side in 38 cadavers (95\%) and normal course in 39 cadavers $(97.5 \%)$, whereas in $10 \%$ variant origin of gonadal artery from renal artery were seen. And $5 \%$ had double gonadal arteries, 2.5\% showed arched course. The gonadal arteries are originated from the abdominal aorta at the level of second lumbar vertebra. Each artery runs obliquely downwards and posterior to the peritoneum on the psoas major muscle. Descending on the posterior abdominal wall, each testicular artery enters the inguinal canal through the deep inguinal ring and accompanies the ductus deferens to testis [10]. With the advancement of newer surgical and diagnostic techniques, understanding of variations of gonadal arteries and their relations to the adjacent structures is essential in avoiding the complications during surgery.

Aberrant gonadal artery: According to Notkovitch $\mathrm{H}$ gonadal arteries of renal origin were found in 14\% of cases taking origin either from the main renal artery or from its branches or from an accessory renal artery [6]. Gonadal artery was found to be arising from renal artery by different authors in percentage range of $3-16.18 \%$ as compared to present study finding of $10 \%$. The observations of major cadaveric studies on variant origin of gonadal artery done by various authors [11-16] and the prevalence of the variations on left and right were tabulated [Table/Fig-7]. Source of table Wadhwa A and Sandeep S [14]. There was no significant side differences observed. Ciçekcibaşi AE et al., found that the gonadal arteries originating from the renal artery are developed from the middle group of lateral mesonephric duct [7]. Shoja MM and Shane $R$ called this variation as aberrant gonadal artery [1]. He revealed that these arteries tend to originate from kidneys which have an accessory arterial supply. He also hypothesised that persistence of aberrant gonadal artery and accessory renal artery are a part of common embryologic error. Though the development of normal vasculogenesis is influenced by many factors, the exact cause for abnormal renal and gonadal arteries is not known. While conducting 
operations near a renal pedicle or in the retroperitoneum [2] the surgeons should be considered about the aberrant origin and course of gonadal arteries.

\begin{tabular}{|l|c|c|c|c|c|}
\hline Authors & $\begin{array}{c}\text { Year of published } \\
\text { article }\end{array}$ & $\begin{array}{c}\text { No. of } \\
\text { cases }\end{array}$ & $\begin{array}{c}\text { Right } \\
\%\end{array}$ & $\begin{array}{c}\text { Left } \\
\%\end{array}$ & $\begin{array}{c}\text { Total } \\
\text { percentage }\end{array}$ \\
\hline $\begin{array}{l}\text { Cauldwell E and } \\
\text { Anson B [11] }\end{array}$ & 2005 & 232 & 5.6 & 4.3 & 10.0 \\
\hline $\begin{array}{l}\text { Pick JW and Anson } \\
\text { BJ [12] }\end{array}$ & 1940 & 50 & 10.0 & 6.1 & 16.1 \\
\hline $\begin{array}{l}\text { Anson BJ and Kurth } \\
\text { LE [13] }\end{array}$ & 1955 & 60 & 3.0 & - & 3.0 \\
\hline Notkovich H [6] & 1955 & 100 & 8.1 & 6.5 & 14.6 \\
\hline $\begin{array}{l}\text { Wadhwa A and } \\
\text { Sandeep S [14] }\end{array}$ & 2010 & 60 & 6.6 & 3.3 & 10.0 \\
\hline Gupta A et al., [15] & 2011 & 60 & 3.3 & 3.3 & 6.6 \\
\hline Mamatha H et al., [16] & 2015 & 40 & 2.5 & 10 & 12.5 \\
\hline Present study & 2021 & 40 & 7.5 & 2.5 & 10.0 \\
\hline
\end{tabular}

A gonadal artery originating from an inferior polar renal artery becomes a major contraindication as it may be injured during the percutaneous treatment of the syndrome of pelviureteral junction [17], the aberrant gonadal artery is of major significance in nephrectomy and renal transplant when aberrant gonadal artery supply the blood to the gonad, without any additional supply from the aorta or any other arterial sources. According to double gonadal arteries majority of case reports were unilateral except by Rusu MC and Paraskevas GK et al., [4,18]. In the present study, double gonadal arteries were seen in 2 cases as unilateral only. So, the preservation and knowledge about the abnormal gonadal arteries are more important to avoid any damage to the gonads. It becomes mandatory to undergo detailed Doppler and ultrasound examination of the renal hilum prior to any surgical intervention [19]. A case of left malignant renal tumour developed infarction of left testis after that case underwent transcatheter embolisation of left renal artery due to the testicular artery and its branches arises from the renal artery [20].

Arched gonadal artery: When the gonadal arteries originated from the renal artery nearer to hilum of the kidney, they were placed lateral to the ureter. In various other sites of origin, they are located medially near their origin, then course on the anterior surface of ureter to be on lateral side. In their descending course the present study agreed with the text book account i.e., right testicular artery passing anterior to inferior vena cava in all cases. In 1 case $(2.5 \%)$ the left testicular artery arose directly from the aorta and arched over the renal vein giving a type III pattern. This type III variation has previously been reported by Notkovitch $\mathrm{H}$, Pick JW and Anson BJ, Anson BJ and Kurth LE [6,12,13]. The arched gonadal arteries arise from the aorta behind or below the renal vein and course upwards to arch over the renal vein. The arched gonadal arteries are important of clinical and surgical point of view [21] as the compression of the renal vein due to looping of the left testicular artery leads to varicocele of left testis. The renal vein hypertension also leads to proteinuria and haematuria. The compression of testicular artery as it passes between two divisions of renal vein leads to degeneration of testis as described by Satheesa NB [22].

The branches of the mesonephric arteries that is caudal to the renal pedicle gives rise to the definitive gonadal arteries as others atrophy. When the kidneys ascend and the gonads descend, the gonadal arteries taking embryological origin from the arteries lying cranial to the renal pedicle will have to undergo an arched course around the renal vein as the kidneys ascends further higher up as in the present cadaveric study. The gonadal artery variations are more on the left-side as the kidney on the left-side ascends further higher up than the rightside [23].

\section{Limitation(s)}

The limitations of this cadaveric study was that it has not been proved experimentally about the origins of the gonadal arteries embryologically.

\section{CONCLUSION(S)}

The observations of this study concluded that the gonadal artery originated from the abdominal aorta in $90 \%$ of the cases and the variant origin of gonadal artery from renal artery was 10\%. Variations were seen both unilateral and bilateral. In 5\% double gonadal arteries were seen. Accessory gonadal arteries took origin from aorta in $2.5 \%$ and from renal artery itself in $2.5 \%$. The presence of such arterial variations is clinically significant during renal surgeries like partial or complete nephrectomy and renal transplants. Renal origin of gonadal artery without accessory from aorta or any other arteries may lead to necrosis of gonad during such surgeries.

\section{Acknowledgement}

Authors were grateful to their respected teachers and the staff of the department for helping them in this study.

\section{REFERENCES}

[1] Shoja MM, Shane R. Origins of the gonadal artery: Embryologic implications. Clin Anat. 2007;20:428-32.

[2] Pai MM, Vadgaonkar R, Rai R, Nayak SR, Jiji PJ, Rande A, et al. A cadaveric study of the testicular artery in the South Indian population Singapore Med J. 2008;49(7) 551-55.

[3] Deepthinath R, Satheesha NB, Mehta RB. Multiple variations in the paired arteries of the abdominal aorta. Clin Anat. 2006;19(6):566-68. Doi: 10.1002/ca.20207, indexed in Pubmed: 16283657.

[4] Rusu MC. Human bilateral doubled renal and testicular arteries with a left testicular arterial arch around the left renal vein. Rom J Morphol Embryol. 2006;47(2):197200. Indexed in Pubmed: 17106531.

[5] Bandopadhyay M, Saha A. Three rare variations in the course of the gonadal artery. Int J Morphol. 2009;27(3):655-58. Doi: 10.4067/s071795022009000300006

[6] Notkovitch $\mathrm{H}$. Testicular artery arching over renal vein: Clinical and pathological considerations with special reference to varicocele. Br J Urol. 1955;27(3):26771. Indexed in Pubmed: 13269815.

[7] Ciçekcibaşi AE, Salbacak A, Seker M. The origin of gonadal arteries in human fetuses: Anatomical variations. AnnAnat. 2002;184(3):275-79. Doi: 10.1016/S09409602(02)80126-1, indexed in Pubmed: 12056759.

[8] Felix W. Manual of human embryology. Keibel F, Mall FP (eds). Lippincott, Philadelphia. 1912:820-825.

[9] Romanes GJ. Cunningham S. manual of practical anatomy. In: The abdomen $15^{\text {th }}$ Edn, Vol 2, Oxford University Press, Newyork, Tokyo, 2000;142-153. Tokyo, 2000;142-153.

[10] Hollinshead WH. Anatomy for surgeons. Harper \& Row, New York. 1971:579-580.

[11] Cauldwell E, Anson B. The visceral branches of the abdominal aorta: Topographical relationships. Am J Anat. 2005;73(1):27-57. Doi: 10.1002/aja.1000730103.

[12] Pick JW, Anson BJ. The renal vascular pedicle. J Urol. 1940;44:411-34.

[13] Anson BJ, Kurth LE. Common variations in the renal blood supply. Surg Gynecol Obstet. 1955;100(2):157-62. Indexed in Pubmed: 13238169.

[14] Wadhwa A, Sandeep S. A study of gonadal arteries in 30 adult human cadavers. Clinical Medicine Insights: Reproductive Health. 2010;4:01-05.

[15] Gupta A, Singal R, Singh D. Variations of Gonadal Artery: Embryological basis and clinical significance. Int J Biol Med Res. 2011;2(4):1006-10.

[16] Mamatha H, D'Souza AS, Vinodhini P. A cadaveric study about the anomolous origin of testicular arteries arising from the accessory renal arteries. Indian J Surg. 2015;77(2):111-16. Doi: 10.1007/s12262-012-0737-8, indexed in Pubmed: 26139964.

[17] Ravery V, Cussenot O, Desgrandchamps F. Variations in arterial blood supply and the risk of hemorrhage during percutaneous treatment of lesions of the pelviureteral junction obstruction: Report of a case of testicular artery arising from an inferior polar renal artery. Surg Radiol Anat. 1993;15:355-59.

[18] Paraskevas GK, Natsis K, Nitsa Z. Bilateral double testicular arteries: A case report and review of the literature. Potential embryological and surgical considerations. Folia Morphol. 2014;73(3):383-88. Doi: 10.5603/ FM.2014.0057, indexed in Pubmed: 25242354

[19] Petru B, Elena S, Dan I, Constantin D. The morphology and the surgical importance of the gonadal arteries originating from the renal artery. Surg Radiol Anat. SRA. 2007;29(5):367.

[20] Siniluoto TM, Hellstrom PA, Paivansalo MJ, Leinonen AS. Testicular infarction following ethanol embolization of a renal neoplasm. Cardiovasc Intervent Radiol. 1988;11(3):162-64. 
[21] Grine FE, Kramer B. Arched gonadal arteries in the South African Negro. J Anat. 1981;132(Pt 3):387-90. indexed in Pubmed: 7298490.

[22] Satheesha NB. Abnormal course of left testicular artery in relation to an abnormal left renal vein: A case report. Kathmandu Univ Med J (KUMJ). 2007;5(1):108-09. indexed in Pubmed: 18603997.
[23] Bergman RA, Afifi AK, Miyauchi R. Illustrated encyclopedia of human anatomic variation: Cardiovascular system: Renal, splenic, and testicular veins. 2008 http://anatomyatlases.org/AnatomicVariants/Cardiovascular/Text/Veins/ RenalSplenicTesticular.shtml

\section{PARTICULARS OF CONTRIBUTORS:}

1. Associate Professor, Department of Anatomy, KAPV Government Medical College, Tiruchirapalli, Tamil Nadu, India.

2. Associate Professor, Department of Anatomy, Government Theni Medical College, Theni, Tamil Nadu, India.

3. Associate Professor, Department of Anatomy, Government Sivagangai Medical College, Sivagangai, Tamil Nadu, India.

NAME, ADDRESS, E-MAIL ID OF THE CORRESPONDING AUTHOR:

Dr Karpaga Jothi,

Associate Professor, Department of Anatomy, Government Theni Medical College,

Theni, Tamil Nadu, India.

E-mail: krpjoe@gmail.com

\section{AUTHOR DECLARATION:}

- Financial or Other Competing Interests: None

- Was Ethics Committee Approval obtained for this study? No

- Was informed consent obtained from the subjects involved in the study? NA

- For any images presented appropriate consent has been obtained from the subjects. NA
PLAGIARISM CHECKING METHODS: [Jain Het al.]

- Plagiarism X-checker: Jan 08, 2021

- Manual Googling: Jun 11, 2021

- iThenticate Software: Jun 19, 2021 (18\%)
ETYMOLOGY: Author Origin

Date of Submission: Dec 30, 2020 Date of Peer Review: Feb 03, 2021

Date of Acceptance: Jun 12, 2021 Date of Publishing: Oct 01, 2021 